\title{
Similarity solutions for the flow and heat transfer over a nonlinear stretching/shrinking sheet in a nanofluid
}

\begin{abstract}
In this paper, a similarity solutions for the flow and heat transfer over a nonlinear stretching/shrinking sheet in a nanofluid is considered. The governing equations are first transformed into a system of non-dimensional via the non-dimensional variables, and then into non-similar ordinary differential equations before they are solved numerically using the shooting method. Numerical results are obtained for the skin friction coefficient and the local Nusselt number as well as the velocity and temperature profiles for some values of the governing parameters, namely the nanoparticle volume fraction ü (0Ößò.2), the value of velocity ratio parameter $\cup^{\circ}$ and the constant exponent $\mathrm{m}$. Three different types of nanoparticles, namely $\mathrm{Cu}, \mathrm{A} 12 \mathrm{O} 3$ and $\mathrm{TiO} 2$ are considered by using water-based fluid with Prandtl number $\operatorname{Pr}=6.2$. It was found that the skin friction and Nusselt number have greater values for $\mathrm{Cu}$ than for $\mathrm{A} 12 \mathrm{O} 3$ and $\mathrm{TiO} 2$. The skin friction coefficient and local Nusselt number increase as the nanoparticle volume fraction ü and constant exponent $\mathrm{m}$ increase. The result also indicate that dual solution exist for a shrinking sheet (lீe Ò ŮÒi 1) for m > 1/3.
\end{abstract}

Keyword: Nanofluid; Nonlinear stretching/shrinking sheet; Similarity solutions 